\title{
TITLE:
}

\section{Formation of unique trimer of nitric oxide on $\mathrm{Cu}(111)$}

\section{$\operatorname{AUTHOR}(\mathrm{S})$ :}

Shiotari, A.; Hatta, S.; Okuyama, H.; Aruga, T.

\section{CITATION:}

Shiotari, A.... [et al]. Formation of unique trimer of nitric oxide on Cu(111). The Journal of Chemical Physics 2014, 141(13): 134705.

\section{ISSUE DATE:}

2014-10-07

URL:

http://hdl.handle.net/2433/191114

\section{RIGHT:}

Copyright 2014 American Institute of Physics. This article may be downloaded for personal use only. Any other use requires prior permission of the author and the American Institute of Physics. 


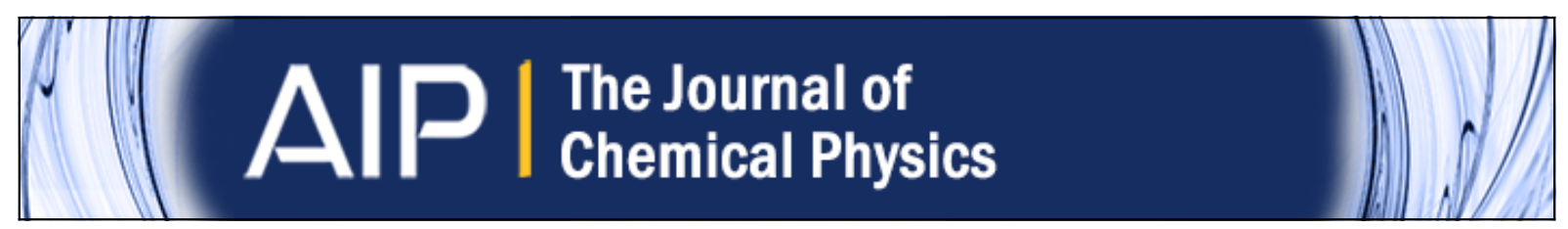

\section{Formation of unique trimer of nitric oxide on $\mathrm{Cu}(111)$}

A. Shiotari, S. Hatta, H. Okuyama, and T. Aruga

Citation: The Journal of Chemical Physics 141, 134705 (2014); doi: 10.1063/1.4896558

View online: http://dx.doi.org/10.1063/1.4896558

View Table of Contents: http://scitation.aip.org/content/aip/journal/jcp/141/13?ver=pdfcov

Published by the AIP Publishing

\section{Articles you may be interested in}

Effects of intrinsic defects on methanthiol monolayers on $\mathrm{Cu}(111)$ : A density functional theory study

J. Chem. Phys. 138, 134708 (2013); 10.1063/1.4799557

A theoretical rationalization of a total inelastic electron tunneling spectrum: The comparative cases of formate and benzoate on $\mathrm{Cu}(111)$

J. Chem. Phys. 136, 244507 (2012); 10.1063/1.4730168

Temperature dependence of conformation, chemical state, and metal-directed assembly of tetrapyridyl-porphyrin on $\mathrm{Cu}(111)$

J. Chem. Phys. 129, 214702 (2008); 10.1063/1.3021291

Surface dynamics of benzenethiol molecules on $\mathrm{Cu}(111)$

Appl. Phys. Lett. 88, 183106 (2006); 10.1063/1.2199969

Interaction of single pentacene molecules with monatomic $\mathrm{Cu} / \mathrm{Cu}$ ( 111 ) quantum wires

J. Vac. Sci. Technol. B 23, 1726 (2005); 10.1116/1.1942508

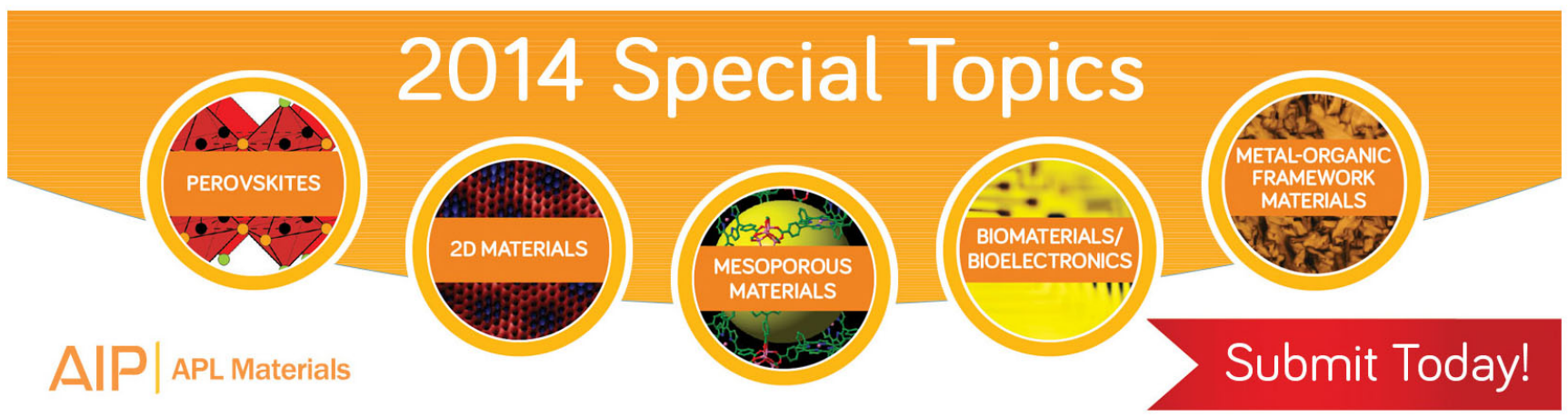




\title{
Formation of unique trimer of nitric oxide on $\mathrm{Cu}(111)$
}

\author{
A. Shiotari, S. Hatta, H. Okuyama, a) and T. Aruga \\ Department of Chemistry, Graduate School of Science, Kyoto University, Kyoto 606-8502, Japan
}

(Received 16 July 2014; accepted 4 September 2014; published online 7 October 2014)

\begin{abstract}
We report that NO molecules unexpectedly prefer a trimeric configuration on $\mathrm{Cu}(111)$. We used scanning tunneling microscopy (STM) at $6 \mathrm{~K}$, and confirmed that the NO molecule is bonded to the face-centered-cubic hollow site in an upright configuration. The individual NO molecule is imaged as a ring protrusion, which is characteristic of the doubly degenerate $2 \pi^{*}$ orbital. A triangular trimer is thermodynamically more favorable than the monomer and dimer, and its bonding structure was characterized by STM manipulation. This unique behavior of $\mathrm{NO}$ on $\mathrm{Cu}(111)$ is ascribed to the threefold symmetry of the surface, facilitating effective mixing of the $2 \pi^{*}$ orbitals in a triangular configuration. () 2014 AIP Publishing LLC. [http://dx.doi.org/10.1063/1.4896558]
\end{abstract}

\section{INTRODUCTION}

NO has a high chemical affinity for metals, and NOmetal interactions are important in chemical syntheses, ${ }^{1}$ biological processes, ${ }^{2}$ and heterogeneous catalysis. ${ }^{3}$ Because of the relevance to catalytic reduction of toxic $\mathrm{NO}_{x}$ from exhaust gases, the reaction, bonding structure, and valence state of $\mathrm{NO}$ on metal surfaces have been studied intensively. ${ }^{4-6}$ As a result of the presence of an unpaired electron in its $2 \pi^{*}$ orbital, the bonding structure is complex, and depends on the coverage and temperature as well as on the nature of the surfaces. One of the important characteristics of NO is that it forms a dimer, $(\mathrm{NO})_{2}$, via overlap of an unpaired electron, on metal surfaces as well as in the gas ${ }^{7}$ and condensed phases. ${ }^{8,9}$ It has been proposed that the catalytic reduction of NO proceeds via the formation of a (NO) $)_{2}$ intermediate on $\operatorname{Ag}(111),{ }^{10-13}$ represented by $2 \mathrm{NO} \rightarrow(\mathrm{NO})_{2} \rightarrow \mathrm{N}_{2} \mathrm{O}+\mathrm{O}$. A similar catalytic reduction mechanism via dimer formation has been proposed on $\mathrm{Cu},{ }^{14-16} \mathrm{Au},{ }^{17-19}$ and transition metal ${ }^{20-22}$ surfaces. Moreover, NO dimers on coinage-metal surfaces have attracted attention because of their photochemical reactions such as NO desorption ${ }^{23,24}$ and reductive $\mathrm{N}_{2} \mathrm{O}$ and $\mathrm{N}_{2}$ formation. ${ }^{25}$ Intermolecular coupling therefore plays an important role in the catalytic reduction of $\mathrm{NO}$ on metal surfaces.

On $\mathrm{Cu}(111)$, the initial adsorption state of $\mathrm{NO}$ at $T$ $\approx 100 \mathrm{~K}$ was reported to be a monomeric species. ${ }^{26-32}$ The bonding geometry was initially proposed to be a bent structure on the bridge site, based on comparison with the $\mathrm{N}-\mathrm{O}$ stretching frequency of nitrosyl complexes. ${ }^{26-28}$ However, the use of the vibrational frequency as a guide to determining the bonding site of NO on a metal surface was questioned, ${ }^{33}$ and an upright NO molecule on the threefold site was proposed as a candidate for the adsorption structure on $\mathrm{Cu}(111) .{ }^{29}$ This was later supported by theoretical calculations. ${ }^{34-37}$ With increasing coverage, NO sequentially forms the $\mathrm{p}(3 \times 3)$ and $(\sqrt{7} \times \sqrt{7}) \mathrm{R} 19.1^{\circ}$ overlayers. ${ }^{29}$ It was proposed that the unit cells were occupied by one $\mathrm{NO}$ molecule at coverages of 0.11 and $0.14 \mathrm{ML}\left(1 \mathrm{ML}=1.76 \times 10^{15}\right.$ molecules $\left./ \mathrm{cm}^{2}\right)$ for the former and latter phases, respectively. On the other hand,

\footnotetext{
a)Electronic mail: hokuyama@kuchem.kyoto-u.ac.jp
}

Sueyoshi et al. ${ }^{28}$ determined the coverage for the $\mathrm{p}(3 \times 3)$ phase to be $0.44-0.56 \mathrm{ML}$, using Auger electron spectroscopy (AES). The structure of the overlayer, i.e., how many NO molecules occupy the unit cell, therefore remains controversial. It was shown that $\mathrm{N}_{2} \mathrm{O}$ formation occurs from these overlayers, ${ }^{29}$ implying that attractive NO-NO coupling occurs in these phases.

In this work, we investigated the adsorbed state of NO on $\mathrm{Cu}(111)$, using scanning tunneling microscopy (STM). Direct imaging of individual NO molecules allows us to determine that the bonding site is the face-centered-cubic (fcc) hollow site. At low temperature ( $15 \mathrm{~K}), \mathrm{NO}$ exists mainly as a monomer, as a result of limited diffusion across the surface. An individual NO molecule is imaged as a characteristic ring, which is ascribed to the doubly degenerate $2 \pi^{*}$ orbital. At elevated temperature $(80 \mathrm{~K})$, NO diffuses and, unexpectedly, forms a trimer with a triangular configuration. The trimeric configuration is therefore thermodynamically stable. This unusual behavior of $\mathrm{NO}$ on a surface is ascribed to the threefold symmetry of the substrate. It was found that the trimer constitutes $\mathrm{p}(3 \times 3)$ and $(\sqrt{7} \times \sqrt{7}) \mathrm{R} 19.1^{\circ}$ overlayers at coverages of 0.33 and $0.43 \mathrm{ML}$, respectively.

\section{EXPERIMENTAL}

The STM experiments were carried out in an ultrahighvacuum chamber at either 6 or $80 \mathrm{~K}$ (USM-1200, Unisoku). An electrochemically etched tungsten tip was used as the STM probe. Single-crystalline $\mathrm{Cu}(111)$ was cleaned by repeated cycles of $\mathrm{Ar}^{+}$sputtering and annealing. The surface was exposed to $\mathrm{NO}$ gas via a tube doser positioned $\sim 1 \mathrm{~cm}$ from the surface, at either 15 or $80 \mathrm{~K}$, through a variable-leak valve. For scanning tunneling spectroscopy (STS), the $\mathrm{d} / / \mathrm{d} V$ curve was obtained numerically from the $I-V$ curve or obtained using a lock-in amplifier with a modulation voltage of $1 \mathrm{mV}_{\text {rms }}$ at $590 \mathrm{~Hz}$, with the feedback loop open. Each spectrum was displayed after subtraction of $\mathrm{d} I / \mathrm{d} V$ obtained over the clean surface at the same tip height. The $\mathrm{d} I / \mathrm{d} V$ images were obtained using a lock-in amplifier with a modulation voltage of $20 \mathrm{mV}_{\text {rms }}$ at $2 \mathrm{kHz}$, with the feedback loop closed. 


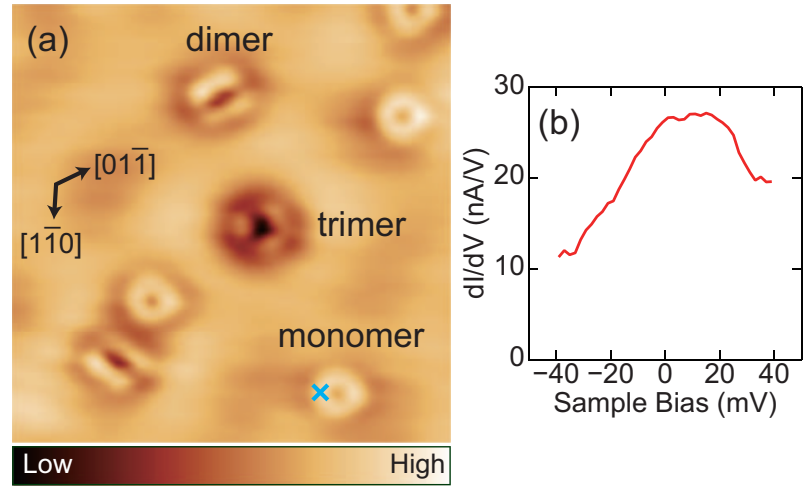

(c)

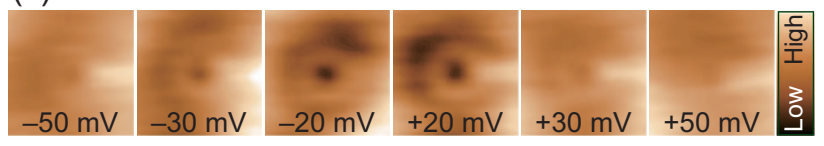

FIG. 1. (a) Typical STM images of $\mathrm{NO} / \mathrm{Cu}(111)$ at $6 \mathrm{~K}$. The surface was exposed to $\mathrm{NO}$ at $15 \mathrm{~K}$. The coverage is less than $0.03 \mathrm{ML}$. The images were acquired in the constant-current mode with a sample bias $V=30 \mathrm{mV}$ and tunneling current $I=5 \mathrm{nA}$. The colored bar corresponds to the topographic height from $-0.38 \AA$ (low) to $0.24 \AA$ (high). (b) The $\mathrm{d} I / \mathrm{d} V$ curve for an isolated $\mathrm{NO}$ molecule obtained by numerical differentiation of $I-V$ recorded over the cross marker in (a), at the tip height corresponding to $V=30 \mathrm{mV}$ and $I=5 \mathrm{nA}$. (c) The $\mathrm{d} I / \mathrm{d} V$ spatial maps recorded at voltages ranging from $V=-50$ to $50 \mathrm{mV}$, with the feedback loop closed $(I=5 \mathrm{nA})$. The image sizes are $50 \AA \times 50 \AA$ for (a) and $13 \AA \times 13 \AA$ for (c).

\section{RESULTS AND DISCUSSION}

Figure 1(a) shows a typical STM image of $\mathrm{Cu}(111)$ exposed to $\mathrm{NO}$ at $15 \mathrm{~K}$. The image was obtained at $6 \mathrm{~K}$. The main feature at low temperature is a ring-shaped protrusion, which is assigned to an isolated NO molecule. Molecular clusters composed of two (dimer) or three (trimer) NO molecules were also observed, as described in detail below. The bonding site of NO is the fcc hollow site, based on the position relative to $\mathrm{Cu}$ adatoms, which are known to be located at the fcc hollow sites ${ }^{42}$ (see Figs. S1 and $\mathrm{S} 2$ in the supplementary material ${ }^{43}$ ). The characteristic ring protrusion directly displays the projection of the doubly degenerate $2 \pi^{*}$ orbital, suggesting that NO is adsorbed in an upright configuration. These results are in agreement with theoretical calculations. ${ }^{34-37}$ Figure 1 (b) shows a $\mathrm{d} / / \mathrm{d} V$ curve recorded over the ring (cross in Fig. 1(a)). The curve shows a peak at the Fermi level, which is ascribed to the $2 \pi^{*}$ state. The complementary $\mathrm{d} I / \mathrm{d} V$ images are displayed in Fig. 1(c). The $\mathrm{d} I / \mathrm{d} V$ images show ring protrusion only near the Fermi level. The doubly degenerate $2 \pi^{*}$ orbital is therefore retained, and partially occupied, on $\mathrm{Cu}(111)$. The molecule belongs to the $C_{3 v}$ point group and the degeneracy of the $2 \pi^{*}$ orbital is retained on the surface. This is in contrast to the case of $\mathrm{NO} / \mathrm{Cu}(110)$, where the twofold symmetry of the surface degrades the molecular symmetry to $\mathrm{C}_{2 v}$, thereby lifting the degeneracy. ${ }^{38,39}$ The width of the $2 \pi^{*}$ resonance is quite small $(\sim 0.1 \mathrm{eV})$, which reflects weak coupling of NO with the $\mathrm{Cu}(111)$ surface ${ }^{40,41}$ Recently, it was revealed, using STM, that NO retains a localized spin moment on $\mathrm{Au}(111)$, giving rise to a Kondo resonance state at $9 \mathrm{~K}^{44}$ This is ascribed to the weak interaction of NO with a coinage-metal

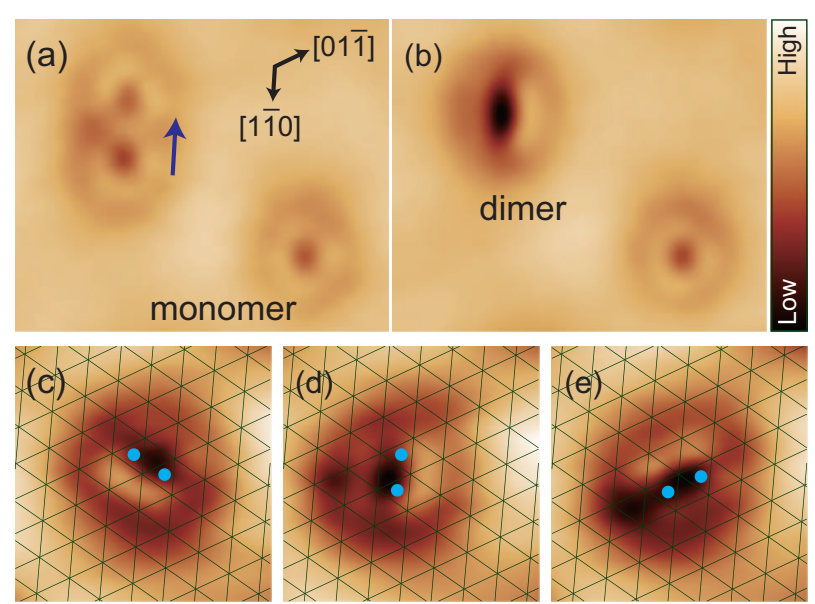

FIG. 2. (a) STM images of three NO molecules on $\mathrm{Cu}(111)$ at $6 \mathrm{~K}(\mathrm{~V}$ $=30 \mathrm{mV}, I=5 \mathrm{nA}$ ). A dimer was produced by manipulating one molecule toward another, as shown by the arrow. (b) STM image of produced dimer, together with remaining monomer. (c)-(e) STM images of dimer in three orientations $(V=30 \mathrm{mV}, I=5 \mathrm{nA})$. Lines represent the lattice of surface $\mathrm{Cu}$ atoms, and the dots indicate the fcc hollow sites, showing the approximate positions of the molecules. The interaction with the STM tip induced the dimer to rotate among (c)-(e). The image sizes are $38 \AA \times 32 \AA$ for (a) and (b), and $18 \AA \times 18 \AA$ for (c)-(e).

surface, resulting in the survival of an unpaired electron in its $2 \pi^{*}$ orbital. ${ }^{13,45,46}$ In contrast, the unpaired electron is readily quenched on transition metal surfaces. ${ }^{35,47}$ The interaction with $\mathrm{Cu}$ surfaces is intermediate between these cases, and our result indicates that the open-shell structure is retained on $\mathrm{Cu}(111)$ as well as on $\mathrm{Cu}(110), ;^{38}$ however it still has to be determined whether or not the magnetic moment is retained.

We produced a dimer and a trimer from individual NO molecules by STM manipulation. Figure 2(a) shows STM images of three NO molecules. STM was used to manipulate the molecule on the left laterally toward another to produce a dimer, as represented by the arrow in Fig. 2(a). The produced dimer is imaged as an oval protrusion, accompanied by a depression (Fig. 2(b)). In the dimer, the $2 \pi^{*}$ orbitals are mixed, giving rise to the characteristic STM image. Figure 2(c) shows the dimer superimposed with a lattice of surface $\mathrm{Cu}$ atoms. The bonding sites of the molecules in the dimer can be inferred from their positions before the manipulation, as shown by the dots in Fig. 2(c). The dots (fcc hollow sites) indicate the approximate positions of $\mathrm{NO}$ molecules in the dimer. The molecules might be tilted and displaced from the ideal threefold position to optimize the interaction. ${ }^{13}$ STM induces the dimer to rotate among the three orientations around a $\mathrm{Cu}$ atom, as shown in Figs. 2(c)-2(e). The rotation is induced even at $V=30 \mathrm{mV}$, which hampers STS measurements over the dimer.

Another NO molecule was manipulated toward the dimer to produce a trimer (Fig. 3(a)). The product is imaged as a triangular depression (Fig. 3(b)). The $\mathrm{Cu}$ lattice was superimposed on the image of the trimer (Fig. 3(d)), showing the registry of the trimer to the surface (Fig. S2 of the supplementary material ${ }^{43}$ ). The approximate positions of the molecules are shown by dots, which are the fcc hollow sites around a $\mathrm{Cu}$ atom. The $\mathrm{d} I / \mathrm{d} V$ curve (Fig. 3(c)) recorded over the 


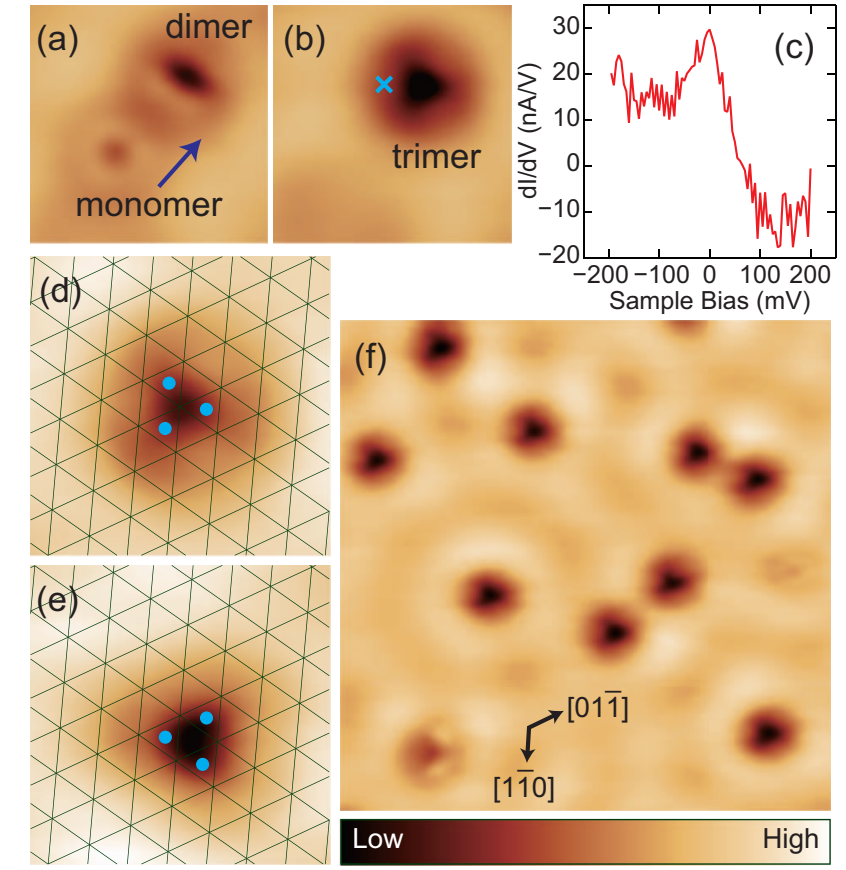

FIG. 3. (a) STM images of monomer and dimer of $\mathrm{NO}$ on $\mathrm{Cu}(111)$ at $6 \mathrm{~K}(\mathrm{~V}$ $=30 \mathrm{mV}, I=5 \mathrm{nA}$ ). A trimer was produced by manipulating the monomer toward the dimer, as shown by the arrow. (b) STM image of produced trimer. (c) $\mathrm{d} I / \mathrm{d} V$ curve for the trimer, recorded over the cross marker in (b) by lock-in detection $\left(1 \mathrm{mV}_{\mathrm{rms}}\right.$ at $\left.590 \mathrm{~Hz}\right)$, at the tip height corresponding to $V=30 \mathrm{mV}$ and $I=5 \mathrm{nA}$. (d) Magnified image of the trimer. The lines represent the lattice of surface $\mathrm{Cu}$ atoms, and the dots indicate the fcc-hollow sites to which NO is bonded. The center of the trimer is the top site. (e) A voltage pulse of $0.5 \mathrm{~V}$ was applied to the trimer in (d), which caused conversion of the trimer to another form with an inequivalent configuration. The center of the second trimer is the hep hollow site. (f) Typical STM image of a $\mathrm{Cu}(111)$ surface at $6 \mathrm{~K}$ after expose to $\mathrm{NO}$ at $80 \mathrm{~K}(V=30 \mathrm{mV}, I=5 \mathrm{nA})$. The coverage is less than $0.03 \mathrm{ML}$. The image sizes are $21 \AA \times 21 \AA$ for (a) and (b), $17 \AA \times 17 \AA$ for (d) and (e), and $85 \AA \times 85 \AA$ for (f).

position between the molecules (cross in Fig. 3(b)) shows a peak at the Fermi level (discussed later). It is remarkable that $\mathrm{NO}$ adopts a trimeric configuration on the surface. Figure 3(f) shows a typical image of $\mathrm{Cu}(111)$ exposed to $\mathrm{NO}$ at $80 \mathrm{~K}$. Depression of the triangular shape is dominant on the surface, which is identical to the case for the trimer produced by manipulation. The trimer is therefore thermodynamically stable on $\mathrm{Cu}(111)$. The trimer is dominant even at low coverage (Fig. 3(f)), suggesting that NO molecules diffuse across the surface and are encountered to form a trimer at $80 \mathrm{~K}$. On application of a voltage pulse of $0.5 \mathrm{~V}$ to the trimer in Fig. 3(d), another trimer with the molecules located around the hexagonal-close-packed (hcp) hollow site was produced (Fig. 3(e), also see Fig. S2 of the supplementary material ${ }^{43}$ ). The trimer in this configuration was not formed spontaneously, and therefore is metastable.

While ionic $\mathrm{NO}$ clusters, including $(\mathrm{NO})_{3}^{+}$and $(\mathrm{NO})_{3}^{-}$, were observed in gas phases (see Refs. 48-50 and references therein), NO trimer formation on surfaces has not been reported. Because the trimer was not observed on the close-packed surfaces of transition metals, ${ }^{51,52}$ the $2 \pi^{*}$ orbital should play an essential role in the trimer formation; it is retained on $\mathrm{Cu}(111)$, but is probably quenched on transitionmetal surfaces. The origin of trimer formation is explained

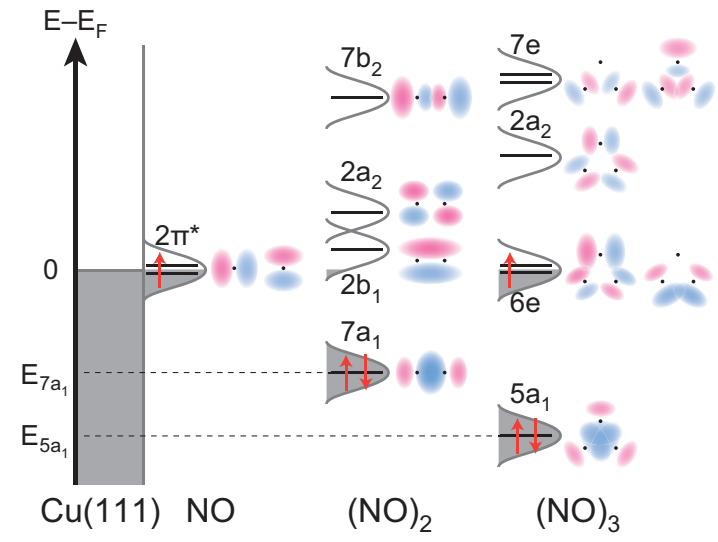

FIG. 4. Schematic energy diagrams of frontier orbitals for free $\mathrm{NO},(\mathrm{NO})_{2}$, and $(\mathrm{NO})_{3}$. These are not calculated but depicted for qualitative argument of the orbital mixing. A red arrow represents occupation by an electron. The molecular orbitals viewed along the axis from the oxygen side are shown. $E_{7 a_{1}}$ and $E_{5 a_{1}}$ represent the energies of the $7 a_{1}$ orbital for $(\mathrm{NO})_{2}$ and the $5 a_{1}$ orbital for $(\mathrm{NO})_{3}$, respectively, with respect to that of the $2 \pi^{*}$ orbital for NO. The $2 \pi^{*}$ and $6 e$ levels for the monomer and trimer, respectively, are observed by STS at the Fermi level (Figs. 1(b) and 3(c)). The STM image of the dimer (Fig. 2(b)) indicates that its $2 b_{1}$ level is broadened and contributes to the density of states at the Fermi level.

in terms of orbital mixing between the molecules on the surface. Figure 4 shows schematic energy diagrams of the frontier orbitals for $\mathrm{NO},(\mathrm{NO})_{2}$, and $(\mathrm{NO})_{3}$. A series of orbitals are depicted (not calculated), according to those for gas-phase molecules. ${ }^{53-55}$ Note that the energy levels are broadened on the surface, as observed in the STS curves for NO (Fig. 1(b)) and $(\mathrm{NO})_{3}$ (Fig. 3(c)). On formation of a dimer, four mixed orbitals are produced with the bonding states occupied, which makes the dimer more stable than the monomer. The oval protrusion observed for the dimer (Fig. 2(b)) reflects the $2 b_{1}$ orbital located near the Fermi level. On formation of a trimer, four mixed orbitals are produced, in which two levels are doubly degenerate. The STM images of the trimer (Figs. 1(a) and $3(d))$ show the shape of $6 e$ orbital, which is observed at the Fermi level in the corresponding STS curve (Fig. 3(c)). The relative stabilities of the dimer and trimer are based qualitatively on the total energy difference of the valence electrons. The energies of the $7 a_{1}$ orbital for the dimer and the $5 a_{1}$ orbital for the trimer with respect to that of the $2 \pi^{*}$ orbital for the monomer (Fermi level) are represented by $E_{7 a_{1}}$ and $E_{5 a_{1}}$, respectively (Fig. 4). The energy gain of the $6 e$ orbital located at the Fermi level is negligible, therefore the stabilization energy of the dimer is $\left|E_{7 a_{1}}\right|$ per molecule, whereas that of the trimer is $\frac{2}{3}\left|E_{5 a_{1}}\right|$. In the case of $\left|E_{5 a_{1}}\right|>1.5\left|E_{7 a_{1}}\right|$, the trimer would therefore be energetically more favorable than the dimer. We propose that this is achieved because of the threefold symmetry of the substrate. The substrate mediates mixing between the $2 \pi^{*}$ orbitals, which is maximized for the trimer in a triangular configuration. Note that we should consider orbital mixing with surface states and charge transfer between the NO molecules and substrate to evaluate the relative stabilities of the trimer and the dimer precisely. A theoretical approach would be helpful in elucidating the origin of this unusual and intriguing behavior of $\mathrm{NO}$ on $\mathrm{Cu}(111)$. 


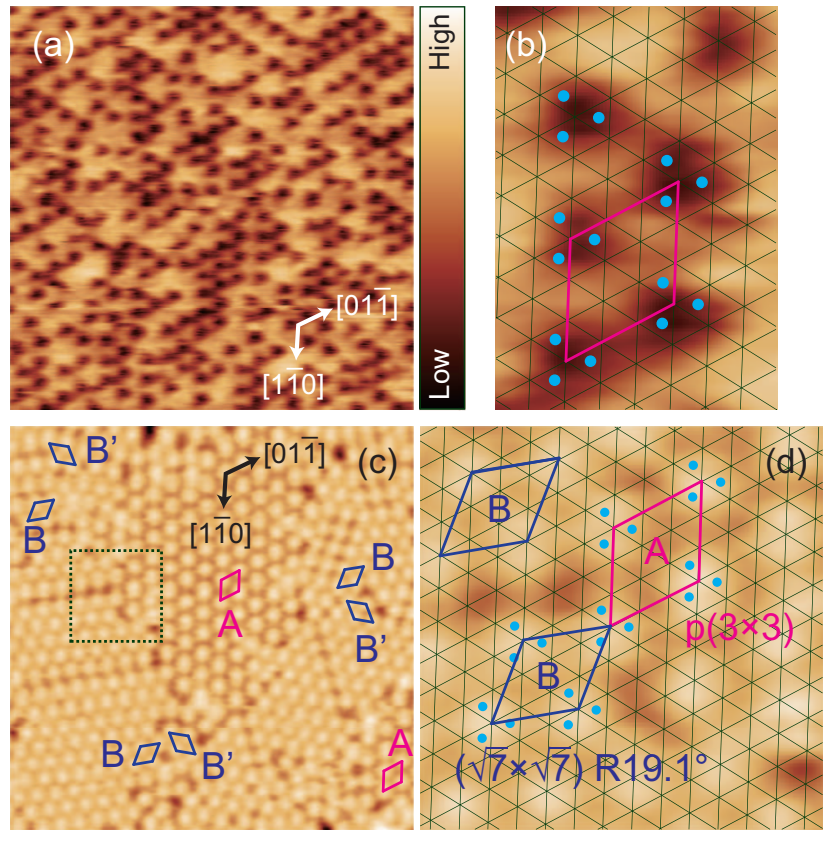

FIG. 5. Typical STM images of $\mathrm{NO} / \mathrm{Cu}(111)$ at high coverages. The surface was exposed to $\mathrm{NO}$ at $80 \mathrm{~K}$ and the images were recorded at the same temperature. (a) The coverage is $0.23 \mathrm{ML}(V=200 \mathrm{mV}, I=2 \mathrm{nA}$ ). NO trimers (triangular depressions) locally form $\mathrm{p}(3 \times 3)$ ordered islands. (b) Magnified image of the island. A rhombus frame shows the $\mathrm{p}(3 \times 3)$ unit cell. (c) The coverage is $0.37 \mathrm{ML}(V=200 \mathrm{mV}, I=1 \mathrm{nA})$. In this image, individual trimers are observed as protrusions. Labels $\mathrm{A}$ and $\mathrm{B}$ show the domains of the $\mathrm{p}(3 \times 3)$ and $(\sqrt{7} \times \sqrt{7}) \mathrm{R} 19.1^{\circ}$ phases, respectively. Red and blue rhombus frames represent the corresponding unit cells. Labels B and $\mathrm{B}^{\prime}$ represent different orientational domains of the $(\sqrt{7} \times \sqrt{7}) \mathrm{R} 19.1^{\circ}$ structure. (d) Magnified image of dotted square in (c). Superimposed dots in (b) and (d) illustrate individual NO molecules in the overlayers. The image sizes are $158 \AA$ $\times 158 \AA$ for (a) and (c), $18 \AA \times 25 \AA$ for (b), and $32 \AA \times 32 \AA$ for (d).

Sueyoshi et al. ${ }^{28}$ observed that as the coverage increased, a $\mathrm{p}(3 \times 3)$ superstructure emerged, for which the NO coverage was estimated to be $0.44-0.56 \mathrm{ML}$ by AES at $100 \mathrm{~K}$. In contrast, Dumas et al. ${ }^{29}$ proposed that the coverage of the $\mathrm{p}(3 \times 3)$ structure was $0.11 \mathrm{ML}$, because they observed a single $\mathrm{N}-\mathrm{O}$ stretching peak by infrared spectroscopy at $88 \mathrm{~K}$, suggesting that only one species is present in the unit cell. Figure 5(a) shows a typical STM image of $\mathrm{NO} / \mathrm{Cu}(111)$ at $80 \mathrm{~K}$. The trimer (triangular depression) is locally arranged with $\mathrm{p}(3 \times 3)$ periodicity. We therefore find that the unit cell of the $\mathrm{p}(3 \times 3)$ structure is occupied by a trimer with a local coverage of 0.33 ML, as shown in Fig. 5(b). Note that the unit cell involves only one equivalent species, and this structural model is consistent with the single peak for the $\mathrm{N}-\mathrm{O}$ stretching mode. ${ }^{29}$ Figure $5(\mathrm{c})$ shows an image of $\mathrm{NO} / \mathrm{Cu}(111)$ at higher coverage $(0.37 \mathrm{ML})$. At this coverage, individual trimers were imaged as protrusions rather than depressions. We postulate that this originates from unavoidable modification of the tip apex by a NO molecule ("molecular" tip; ${ }^{.6}$ Fig. S3 of the supplementary material ${ }^{43}$ ). In Fig. 5(c), the domains of $\mathrm{p}(3 \times 3)$ and $(\sqrt{7} \times \sqrt{7}) \mathrm{R} 19.1^{\circ}$ structures coexist, and are labeled A and B, respectively. The unit cells are represented by rhombus frames. The labels B and $\mathrm{B}^{\prime}$ represent different orientational domains. The area of the $(\sqrt{7} \times \sqrt{7}) \mathrm{R} 19.1^{\circ}$ domain $\left(\mathrm{B}\right.$ and $\left.\mathrm{B}^{\prime}\right)$ is around twice as large as that of the $\mathrm{p}(3 \times 3)$ domain $(\mathrm{A})$, while the former phase was not observed at lower coverage (Fig. 5(a)). This is consistent with the previous observation that the $\mathrm{p}(3 \times 3)$ phase was replaced by the $(\sqrt{7} \times \sqrt{7}) \mathrm{R} 19.1^{\circ}$ phase as the coverage increased. ${ }^{29}$ It is likely that the $(\sqrt{7} \times \sqrt{7}) \mathrm{R} 19.1^{\circ}$ phase also consists of a trimer, with a local coverage of $0.43 \mathrm{ML}$. The "trimer-unit" model proposed in this work is therefore in full agreement with the results of previous experiments.

\section{CONCLUSIONS}

In summary, we investigated the adsorption and valence states of $\mathrm{NO}$ on $\mathrm{Cu}(111)$, using STM. Individual NO molecules adsorbed at $15 \mathrm{~K}$ show a ring protrusion characteristic of the doubly degenerate $2 \pi^{*}$ orbital. The $2 \pi^{*}$ orbital is partially filled, suggesting that the NO monomers remain radicals, and can therefore interact with each other through electronic coupling. At elevated temperatures, the molecules aggregate to form a dimer and then a trimer. The electronic coupling is possibly maximized in a triangular configuration on $\mathrm{Cu}(111)$, giving rise to the unexpected trimer formation. We propose a new structural model for the overlayers of $\mathrm{NO} / \mathrm{Cu}(111)$. The trimer constitutes the $\mathrm{p}(3 \times 3)$ and $(\sqrt{7} \times \sqrt{7}) \mathrm{R} 19.1^{\circ}$ overlayers at coverages of 0.33 and $0.43 \mathrm{ML}$, respectively.

\section{ACKNOWLEDGMENTS}

A.S. acknowledges the support of the Japan Society for the Promotion of Science.

${ }^{1}$ T. W. Hayton, P. Legzdins, and W. B. Sharp, Chem. Rev. 102, 935 (2002).

${ }^{2}$ Nitric Oxide Part B: Physiological and Pathological Processes, Methods in Enzymology Vol. 269, edited by L. Packer (Elsevier, Amsterdam, 1996).

${ }^{3}$ Y. Hu, K. Griffiths, and P. R. Norton, Surf. Sci. 603, 1740 (2009).

${ }^{4}$ P. D. Johnson and S. L. Hulbert, Phys. Rev. B 35, 9427 (1987).

${ }^{5}$ W. A. Brown and D. A. King, J. Phys. Chem. B 104, 2578 (2000).

${ }^{6}$ N. Sheppard and C. De La Cruz, Phys. Chem. Chem. Phys. 12, 2275 (2010).

${ }^{7}$ C. E. Dinerman, J. Chem. Phys. 53, 626 (1970).

${ }^{8}$ A. L. Smith, W. E. Keller, and H. L. Johnston, J. Chem. Phys. 19, 189 (1951).

${ }^{9}$ E. M. Nour, L. H. Chen, and M. M. Strube, J. Phys. Chem. 88, 756 (1984).

${ }^{10}$ R. J. Behm and C. R. Brundle, J. Vac. Sci. Technol., A 2, 1040 (1984).

${ }^{11}$ W. A. Brown, P. Gardner, and D. A. King, J. Phys. Chem. 99, 7065 (1995).

${ }^{12}$ C. I. Carlisle and D. A. King, J. Phys. Chem. B 105, 3886 (2001).

${ }^{13}$ Z.-P. Liu, S. J. Jenkins, and D. A. King, J. Am. Chem. Soc. 126, 7336 (2004).

${ }^{14}$ W. A. Brown, R. K. Sharma, D. A. King, and S. Haq, J. Phys. Chem. 100, 12559 (1996).

${ }^{15}$ C. M. Kim, C.-W. Yi, and D. W. Goodman, J. Phys. Chem. 106, 7065 (2002).

${ }^{16}$ S. Haq and R. Raval, Phys. Chem. Chem. Phys. 9, 3641 (2007).

${ }^{17}$ T.-D. Chau, T. V. de Bocarme, and N. Kruse, Catal. Lett. 98, 85 (2004).

${ }^{18}$ Y. Wang, D. Zhang, Z. Yu, and C. Liu, J. Phys. Chem. C 114, 2711 (2010).

${ }^{19}$ Z. Wu, L. Xu, W. Zhang, Y. Ma, Q. Yuan, Y. Jin, J. Yang, and W. Huang, J. Catal. 304, 112 (2013).

${ }^{20}$ E. Baldwin and C. Friend, J. Phys. Chem. 89, 2576 (1985).

${ }^{21}$ K. T. Queeney and C. M. Friend, J. Chem. Phys. 107, 6432 (1997).

${ }^{22}$ A. Beniya, T. Koitaya, H. Kondoh, K. Mukai, S. Yoshimoto, and J. Yoshinobu, J. Chem. Phys. 131, 084704 (2009).

${ }^{23}$ R. T. Kidd, D. Lennon, and S. R. Meech, J. Phys. Chem. B 103, 7480 (1999).

${ }^{24}$ N. G. Rey and H. Arnolds, J. Chem. Phys. 135, 224708 (2011).

${ }^{25}$ K. H. Kim, K. Watanabe, D. Menzel, and H.-J. Freund, J. Am. Chem. Soc. 131, 1660 (2009); Surf. Sci. 606, 1142 (2012). 
${ }^{26}$ J. F. Wendelken, J. Vac. Sci. Technol. 20, 884 (1982).

${ }^{27}$ S. K. So, R. Franchy, and W. Ho, J. Chem. Phys. 95, 1385 (1991).

${ }^{28}$ T. Sueyoshi, T. Sasaki, and Y. Iwasawa, J. Phys. Chem. 100, 13646 (1996).

${ }^{29}$ P. Dumas, M. Suhren, Y. J. Chabal, C. J. Hirschmugl, and G. P. Williams, Surf. Sci. 371, 200 (1997).

${ }^{30}$ B. Chen, Y. Ma, L. Ding, L. Xu, Z. Wu, Q. Yuan, and W. Huang, Chin. J. Catal. 34, 964 (2013).

${ }^{31}$ D. W. Johnson, M. H. Matloob, and M. W. Roberts, J. Chem. Soc., Faraday Trans. 75(1), 2143 (1979).

${ }^{32}$ I. Kinoshita, A. Misu, and T. Munakata, J. Chem. Phys. 102, 2970 (1995).

${ }^{33}$ M. C. Asensio, D. P. Woodruff, A. W. Robinson, K. M. Schindler, P. Gardner, D. Ricken, A. M. Bradshaw, J. C. Conesa, and A. R. Gonzalez-Elipe, Chem. Phys. Lett. 192, 259 (1992).

${ }^{34}$ A. Bogicevic and K. C. Hass, Surf. Sci. 506, L237 (2002).

${ }^{35}$ M. Gajdoš, J. Hafner, and A. Eichler, J. Phys.: Condens. Matter 18, 13 (2006).

${ }^{36}$ M.-Y. Yen and J.-J. Ho, Chem. Phys. 373, 300 (2010).

${ }^{37}$ A. A. B. Padama, H. Kishi, R. L. Arevalo, J. L. V. Moreno, H. Kasai, M. Taniguchi, M. Uenishi, H. Tanaka, and Y. Nishihata, J. Phys.: Condens. Matter 24, 175005 (2012)

${ }^{38}$ A. Shiotari, Y. Kitaguci, H. Okuyama, S. Hatta, and T. Aruga, Phys. Rev. Lett. 106, 156104 (2011).

${ }^{39}$ A. Shiotari, H. Okuyama, S. Hatta, and T. Aruga, Chem. Sci. 5, 922 (2014).

${ }^{40}$ J. W. Gadzuk, Surf. Sci. 43, 44 (1974).

${ }^{41}$ J. K. Norskøv, Rep. Prog. Phys. 53, 1253 (1990).
${ }^{42}$ J. Repp, G. Meyer, K.-H. Rieder, and P. Hyldgaard, Phys. Rev. Lett. 91, 206102 (2003).

${ }^{43}$ See supplementary material at http://dx.doi.org/10.1063/1.4896558 for the binding site of $\mathrm{NO}$ on $\mathrm{Cu}(111)$ and STM images with bare metal and "molecular" tips.

${ }^{44}$ R. Requist, S. Modesti, P. P. Baruselli, A. Smogunov, M. Fabrizio, and E. Tosatti, Proc. Natl. Acad. Sci. U.S.A. 111, 69 (2014).

${ }^{45}$ A. Yoshimori, Surf. Sci. 342, L1101 (1995).

${ }^{46}$ M. P. Jigato, D. A. King, and A. Yoshimori, Chem. Phys. Lett. 300, 639 (1999).

${ }^{47}$ Q. Ge and D. A. King, Chem. Phys. Lett. 285, 15 (1998).

${ }^{48}$ I. Panas, A. Snis, F. Acke, and T. Johnson, Chem. Phys. Lett. 302, 431 (1999).

${ }^{49}$ T. Tsukuda, L. Zhu, M. Saeki, and T. Nagata, Int. J. Mass Spectrom. 220, 137 (2002)

${ }^{50}$ M. A. Odeneye and A. J. Stace, Phys. Chem. Chem. Phys. 7, 998 (2005).

${ }^{51}$ M. Matsumoto, N. Tatsumi, K. Fukutani, T. Okano, T. Yamada, K. Miyake, K. Hate, and H. Shigekawa, J. Vac. Sci. Technol., A 17, 1577 (1999).

${ }^{52}$ M. Matsumoto, S. Ogura, K. Fukutani, and T. Okano, Surf. Sci. 603, 2928 (2009).

${ }^{53}$ M. P. Jigato, V. Termath, P. Gardner, N. C. Handy, D. A. King, S. Rassias, and M. Surman, Mol. Phys. 85, 619 (1995).

${ }^{54}$ H. A. Duarte, E. Proynov, and D. R. Salahub, J. Chem. Phys. 109, 26 (1998).

${ }^{55}$ T. A. Albright, J. K. Burdett, and M.-H. Whangbo, Orbital Interactions in Chemistry, 2nd ed. (John Wiley \& Sons, New Jersey, 2013).

${ }^{56}$ L. Bartels, G. Meyer, and K.-H. Rieder, Surf. Sci. 432, L621 (1999). 